\title{
Thermo-Mechanical Properties of Urea-Based Pattern Molding Compounds for Investment \\ Casting
}

\author{
Hilary Rutto and Walter W. Focke* \\ IAM, Department of Chemical Engineering, University of Pretoria, \\ walter.focke@up.ac.za Tel. 0027124203728 Fax 0027124202516
}

\begin{abstract}
Urea is a low cost material with thermal and mechanical properties suitable for use in investment casting pattern molding compounds. Conventional compounds are made by a "cooking" process wherein the urea is added to and dissolved in an aqueous solution of a water soluble polymer followed by evaporation of the water. Here we describe novel formulations based on either polyvinyl alcohol (PVOH) plasticized by glycerol or ethylene vinyl acetate (EVA) resins together with wax that can be prepared by a facile twin-screw compounding process. The thermo-mechanical properties of these compounds were characterized using differential scanning calorimetry (DSC), thermo gravimetric analysis (TGA), dynamic mechanical analysis (DMA) and three bend point tests. The PVOH-based molding compounds featured better mechanical properties than those based on EVA. Increasing the polymer content produced weaker but tougher molding compounds. Increasing wax content improved stiffness but resulted in a loss of toughness. The TG results showed that both compounds decomposed readily at elevated temperatures and left less than $3 \mathrm{wt}$. $\%$ ash at $800^{\circ} \mathrm{C}$
\end{abstract}

Keywords: Urea; investment casting; molding compound; mechanical properties; EVA. 


\section{Introduction}

Metals are essential industrial materials due to their good mechanical properties. Metal parts are produced by means of forming processes such as casting, forging, and extrusion. Investment casting is a versatile, flexible process capable of producing "near net shape" metal components. Traditional investment casting involves the following key steps: Making a disposable pattern by injecting wax into a metal mould; building a ceramic shell mould layer-by-layer by repeated dipping of the pattern in ceramic slurries; dewaxing the green ceramic shell; firing it to prepare the final ceramic mould; casting the molten metal into the shell mould, and removal of the shell by mechanical or chemical means to leave the final metal part (Black et al., 1984).

The pattern molding material should feature the following properties (Fielder, 1995; Fujita, 1995; Fielder, 1998; Sabau and Viswanathan, 2003): It must be strong enough not to break during the handling, assembly and storage steps. It should not shrink or distort, or stress the ceramic mould. It should not react with the refractory mould material, impart a rough surface finish or leave an appreciable ash residue after removal. Finally environmentally friendly materials are preferred.

Urea-based molding compounds are occasionally used in stead of wax. Conventional ureabased molding compounds are produced using a "cooking" process (Fujita, 1995). This entails the high temperature dissolution of the polymer binder, i.e. poly(vinyl alcohol) $(\mathrm{PVOH})$ and the urea in a water-ethanol mixture followed by evaporation of the solvents. This batch-type process is energy intensive and time consuming. Consequently this study investigated whether such compounds can be produced by conventional polymer compounding techniques.

Urea is a low cost material with good thermal and mechanical properties. Its widespread availability, low melting point and low toxicity makes it an attractive filler material for investment casting pattern molding compounds. It has a unique ability to form inclusion compounds and also forms low melting eutectics (Sekiguchi and Obi, 1961; White, 1998). Unfortunately urea degrades just above its melting point of ca. $134{ }^{\circ} \mathrm{C}$ to produce gaseous ammonia and carbon dioxide. 
Poly(vinyl alcohol) (PVOH) is a biodegradable polymer with wide-ranging applications. However, its melting temperature exceeds the thermal degradation onset temperature of ca. $170{ }^{\circ} \mathrm{C}$. Plasticization of PVOH allows suitable lowering of the melting point (Jang and Lee, 2003). Glycerol was chosen as plasticizer due to its compatibility with $\mathrm{PVOH}$ and its high boiling point (George, 2004). The use of a hot-melt adhesive base, i.e. poly(ethylene-co-vinyl acetate) (EVA), as binder was also explored. EVA is available in a wide range of high melt flow index grades and low melting temperatures suitable for use with urea. Waxes feature very low melt viscosities combined with weak adhesion to metal surfaces. A paraffin wax was used as lubricant and mould release agent.

This study focused on the development of compoundable investment-casting molding compounds that meet the "near net shape" metal standard. Requirements include low apparent melt viscosity to aid penetration into thin sections as well as ease of injection of the pattern material into the metal mould; low solidification shrinkage to guarantee retention of the required dimensions during the injection molding step; acceptable mechanical properties to avoid breakage of the patterns; good wettability by the ceramic slurries and low surface roughness; low thermal expansion to aid removal from the green shell, and low ash content to avoid residue formation. However, this study is limited to the investigation of selected thermo-mechanical properties of two urea-filled polymer systems with a wax. The binders considered for urea were EVA and poly(vinyl alcohol) (PVOH) plasticized with glycerol. The EVA is lipophilic and should show weaker interactions with the urea and stronger ones with the wax component. The PVOH is highly hydrophilic and is expected to interact strongly with the urea.

\section{Materials and Experimental Procedures}

Materials: Fertilizer grade urea was used. The glycerol (CP grade) was obtained from Promark Chemical. Paraffin wax grade M3X was supplied by Sasol-Schumann (Melting point: 60- 
$65{ }^{\circ} \mathrm{C}$; density: $750 \mathrm{~kg} / \mathrm{m}^{3}$ ). The poly(vinyl alcohol) grade was Celvol 504 supplied by Celanese (degree of hydrolysis 87-89 \%). EVA grade Elvax 210 was supplied by DuPont (28\% VA content; $\mathrm{MFI}=400 \mathrm{dg} / \mathrm{min} @ 190{ }^{\circ} \mathrm{C} / 2.16 \mathrm{~kg}$; density: $\left.951 \mathrm{~kg} / \mathrm{m}^{3}\right)$.

Compounding: All compositions considered are presented in Table 1. Compositions are reported on a mass basis with $\mathrm{X} / \mathrm{Y} / \mathrm{Z}$ corresponding to the urea/binder/wax content expressed in weight percent. Note that the PVOH binder refers to the plasticized polymer. In the PVOH-based formulations, binder and wax contents of 5, 10 and 15 wt. \% each were considered in various combinations. Higher polymer contents were also explored in the EVA formulations. Before use, the urea prills were milled down to a particle size of ca. $150 \mu \mathrm{m}$.

Table 1. Formulations tested with compositions indicated in wt. \%

\begin{tabular}{cccccccccc}
\hline Urea & 70 & 75 & 75 & 80 & 80 & 80 & 85 & 85 & 90 \\
PVOH* & 15 & 10 & 15 & 5 & 10 & 15 & 5 & 10 & 5 \\
Wax & 15 & 15 & 10 & 15 & 10 & 5 & 10 & 5 & 5 \\
\hline Urea & 60 & 65 & 65 & 70 & 70 & 70 & 70 & 75 & 75 \\
EVA & 30 & 20 & 25 & 15 & 20 & 20 & 25 & 10 & 15 \\
Wax & 10 & 15 & 10 & 15 & 10 & 10 & 5 & 15 & 10 \\
\hline Urea & 75 & 75 & 80 & 80 & 80 & 80 & 85 & & \\
EVA & 20 & 20 & 5 & 10 & 15 & 15 & 10 & \\
Wax & 5 & 5 & 15 & 10 & 5 & 5 & 5 & & \\
\hline & * Plasticized PVOH (80 parts glycerol per 100 parts polymer)
\end{tabular}

The PVOH powder (100 parts) was mixed with 80 parts glycerol using a stirring rod. It was then conditioned in a laboratory oven at $80{ }^{\circ} \mathrm{C}$ for $8 \mathrm{~h}$. This $\mathrm{PVOH} / \mathrm{glycerol}$ blend was then thoroughly mixed on a laboratory two-roll mill set at a temperature of $110^{\circ} \mathrm{C}$. Once the $\mathrm{PVOH}-$ glycerol mixture fluxed, the urea and wax powders were added portion-wise and mixed in. The resulting sheets were granulated.

The compounding of the EVA formulations was done at $20 \mathrm{~kg} / \mathrm{h}$ and $400 \mathrm{rpm}$ using a 40 mm, 42 L/D Berstorff Model EV 40 co-rotating twin screw extruder. The temperature profile was set to increase gradually from $100{ }^{\circ} \mathrm{C}$ at the feed zone to $110^{\circ} \mathrm{C}$ at the die. The data for the PVOH- 
based compounds reported here, were obtained from samples prepared on a two-roll mill. However, additional trials were conducted to confirm that these materials can be prepared by extrusion compounding on the same twin screw extruder.

Test specimens, conforming to ASTM D638, were injection molded on an Engel 3040 machine with a clamping force of $800 \mathrm{kN}$. The injection molder temperatures were set to $110^{\circ} \mathrm{C}$ and that of the mould at $30{ }^{\circ} \mathrm{C}$. Injection molding was done at an average injection speed of 20 $\mathrm{mm} / \mathrm{s}$, a cooling time of 15 seconds, a hold time of 10 seconds and a hold-on pressure of 90 bar.

Characterization: Mechanical properties were quantified using the ASTM D790 three point bend test. Six samples of dimensions $4 \mathrm{~mm}$ x $10 \mathrm{~mm}$ x $80 \mathrm{~mm}$ of each type of formulation were tested in accordance with the ASTM Standard. The samples were stored under ambient conditions for $24 \mathrm{~h}$ before testing on a Series IX Instron tensile tester fitted with a $5 \mathrm{kN}$ load cell. All tests were performed using a crosshead speed of $1.8 \mathrm{~mm} / \mathrm{min}$ with the load applied over a $64 \mathrm{~mm}$ support span. The "maximum load, maximum deflection" value was used to calculate the flexural strength and the modulus of elasticity.

The melt flow index (MFI) was measured at $120{ }^{\circ} \mathrm{C} / 2.16 \mathrm{~kg}$. It proved impossible to obtain reliable data with the urea-wax- $\mathrm{PHOH}$ compounds because gross phase separation took place during the heating stage. This behavior was not shown by the urea-EVA-wax compounds.

Charpy impact strength was determined using a Zwick pendulum tester. Ten unnotched specimens of dimensions $50 \mathrm{~mm} \times 10 \mathrm{~mm} \times 4 \mathrm{~mm}$ were cut and machined from injection molded tensile test pieces.

Dynamic mechanical analysis (DMA) was done on a Perkin-Elmer DMA 7e instrument at temperatures ranging from -50 to $150{ }^{\circ} \mathrm{C}$ at $10 \mathrm{~Hz}$. The test pieces were obtained from the injection-molded samples that were cut and machined into rectangular bars of dimensions $10 \mathrm{~mm} \mathrm{x}$ $10 \mathrm{~mm} \times 4 \mathrm{~mm}$. 
Thermomechanical analysis (TMA) was done on a Perkin Elmer instrument. The injectionmolded specimens were cut and machined into rectangular bars similar to those prepared for DMA. Temperature was scanned from 25 to $150{ }^{\circ} \mathrm{C}$ at a heating rate of $5^{\circ} \mathrm{C} / \mathrm{min}$ using a static force of $1 \mathrm{~N}$ and a spherical probe with a diameter of $1 \mathrm{~mm}$. Vicat softening points were determined with a load of $10 \mathrm{~N}$ applied to the specimen. The softening temperature was taken as the point at which the probe penetration reached $1 \mathrm{~mm}$.

A Mettler Toledo A851 simultaneous TGA/SDTA machine was used for thermo-gravimetric (TG) analysis. Powder samples (ca. $10 \mathrm{mg}$ ) were placed in an open $70 \mu \mathrm{L}$ alumina pan and heated from $25{ }^{\circ} \mathrm{C}$ to $800{ }^{\circ} \mathrm{C}$ at a scan rate of $10^{\circ} \mathrm{C} / \mathrm{min}$ in air.

Differential Scanning Calorimetry (DSC) was performed on a Perkin-Elmer DSC 7 machine. Samples were heated from $30{ }^{\circ} \mathrm{C}$ to $140{ }^{\circ} \mathrm{C}$ at a heating rate of $5{ }^{\circ} \mathrm{C} / \mathrm{min}$. The final temperature was maintained for 1 minute. Thereafter the temperature was ramped down at a cooling rate of $5^{\circ} \mathrm{C} / \mathrm{min}$.

\section{Results and Discussion}

The following framework hypotheses are posited to aid interpretation of the experimental observations. In turn, they are justified by their ability to rationalize the combined and diverse data presented below. Urea, glycerol and PVOH are highly polar compounds while the wax and EVA are nonpolar. Despite this, liquid wax can interact with solid urea to form a clathrate, i.e. an inclusion compound. In such compounds the wax chains are trapped inside open channels in the urea crystals. However, the fast cooling rate enforced during the injection molding step locked-in non-equilibrium solid state phases. Consequently the clathrate formation was kinetically limited and most likely did not reach equilibrium levels. Nonetheless the wax has a greater affinity for EVA and these two components formed a compatible blend. They co-crystallize, the wax acting as reinforcement for the EVA and chain segments of the latter being incorporated into the wax 
crystals. Owing to its higher molar mass, the EVA in turn toughens the wax by providing tiemolecule connections between neighboring wax crystallites. The low compatibility of these components with urea means that these compounds should simply be viewed as highly filled urea composites with weak interfacial bonding between the filler and polymer-wax phases. In the molten state the wax acts as internal lubricant as it interacts and dissolves in the EVA polymer.

The opposite appears to be the case for $\mathrm{PVOH}$ as binder. Here too, the urea forms a solid filler phase. However, strong hydrogen bonding interaction between the urea and the hydroxyl groups of the PVOH provides for enhanced interfacial adhesion. Urea-wax clathrate formation is expected to be more likely with this binder as the PVOH has no affinity for the wax. Another factor is the difference in molecular mass. The PVOH has a much higher molecular mass than the EVA binder used here.

\subsection{Thermal Properties}

Thermal behavior related to melting and crystallization of the molding compounds are relevant during the pattern shaping step (injection molding) as well as during the "wax" removal operation from the green ceramic shells. DSC was used to characterize the calorimetric properties of the pattern materials. The DSC heating runs for the pure components revealed melting ranges of 50-55 ${ }^{\circ} \mathrm{C}$ and $55-61{ }^{\circ} \mathrm{C}$ for the wax and EVA respectively. The urea melting peak was centered at ca. $132{ }^{\circ} \mathrm{C}$ and, on cooling it showed a sharp crystallization peak at $108{ }^{\circ} \mathrm{C}$. The wax and EVA showed broader crystallization exotherms with peaks located at $55{ }^{\circ} \mathrm{C}$ and $57^{\circ} \mathrm{C}$ respectively. The DSC curves for PVOH plasticized with glycerol were featureless in the temperature range $25{ }^{\circ} \mathrm{C}$ to $140{ }^{\circ} \mathrm{C}$ consistent with an essentially amorphous structure. 


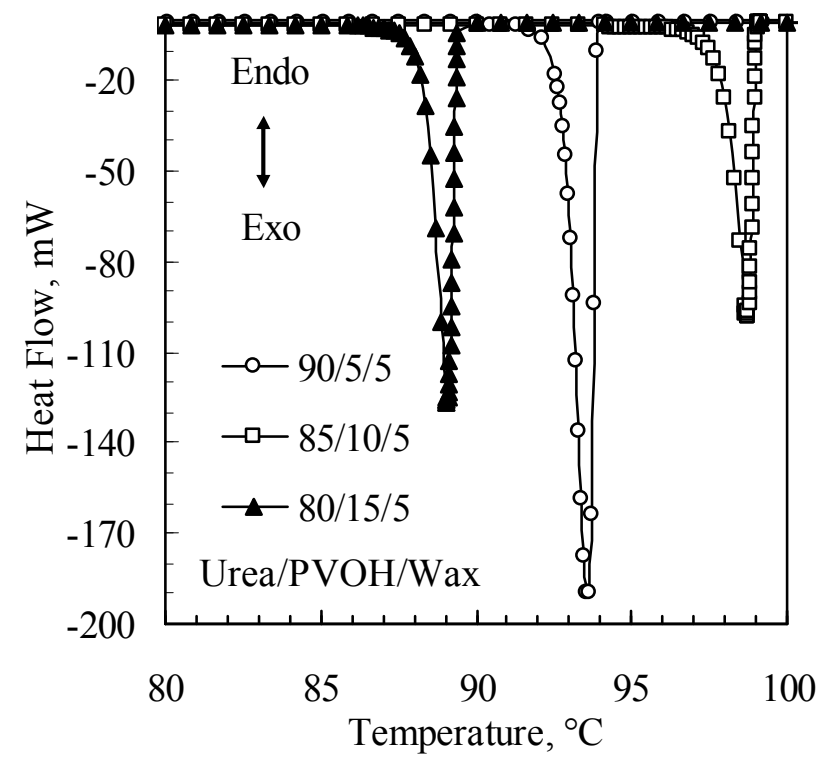

A

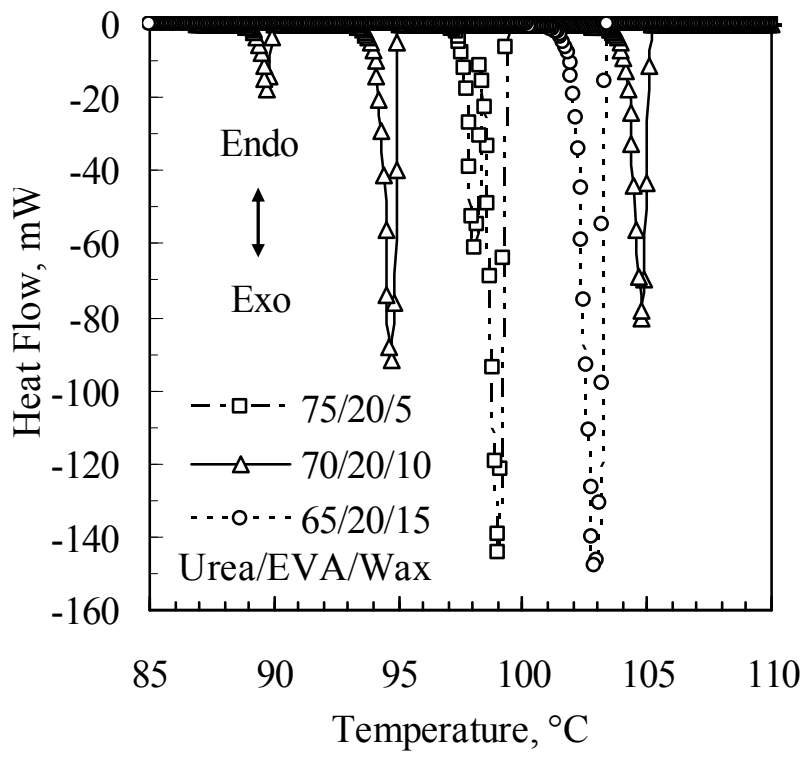

$\mathrm{B}$

Figure 1. A. Effect of increasing the polymer content and of increasing wax content on the DSC cooling curves for the (A) PVOH and (B) EVA pattern molding compounds respectively.

The DSC scans for the PVOH compounds showed multiple thermal events. Formulations with high wax content showed three endothermic peaks in the heating curve and three exothermic peaks in the cooling curve. The endothermic peak centered at ca. $50^{\circ} \mathrm{C}$ is assigned to the melting of free wax. The large endothermic peak at ca. $120^{\circ} \mathrm{C}$ is due to the melting of urea. The intensity of this peak decreases with increasing wax content and another peak above $135^{\circ} \mathrm{C}$ develops. The latter is attributed to the formation of a wax-urea inclusion compound, i.e. a clathrate.

The location of the cooling exotherm peak provides an indication of the ease of crystallization of the compound. If significant under-cooling is required before the compound starts to crystallize, it implies that crystallization is lethargic. The need for fast cycle times in injection molding imply that rapid crystallization is desired. Figure 1 shows the effect of PVOH content at a constant wax level of $5 \%$. The composition with $15 \% \mathrm{PVOH}$ required the largest under-cooling before crystallization commenced. Crystallization is expected to be retarded by the high melt viscosity imparted by the presence of the high molar mass polymer. However, crystallization 
occurred fastest at the intermediate PVOH content of $10 \%$. The reason for this complex behavior and nonlinear composition dependence is not understood at present.

The thermal behavior of the EVA-based compounds can be summarized as follows: The DSC results show two endothermic peaks on heating and multiple exothermic peaks on cooling respectively. The small lower melting peak at ca. $60{ }^{\circ} \mathrm{C}$ corresponds to the EVA and wax present in the blend. The EVA and paraffin wax crystallize in the same temperature range. The large melting endotherm at ca. $133^{\circ} \mathrm{C}$ is identical to that observed for neat urea. Since the presence of the wax and EVA did not lead to a melting point depression, one can conclude that they are completely insoluble in each other in the molten state.

The effects of increasing the polymer and wax content on the cooling curve exotherms were also investigated. The latter effect is shown in Figure 1B for EVA compounds containing 20 wt. \% polymer. Multiple exothermic peaks are more pronounced at high wax content (15 wt. \%). There is no consistent trend with respect to the effect of the wax or polymer content on the position of the endotherm peaks. The multiplicity of endotherms events is tentatively attributed to the formation of inclusion compounds with different crystallization behaviors. This interpretation is partially supported by the fact that the combined enthalpies of crystallization for the events occurring above $80{ }^{\circ} \mathrm{C}$ increased slightly with decrease in urea content.

\subsection{Melt Flow Index}

The melt flow index provides a rough indication of the ease of injection of the pattern material into the metal mold and of its ability to penetrate thin sections. Figure 2 shows the effect of composition on the MFI of the EVA-based compounds. It varied over several orders of magnitude in the composition range investigated. The apparent fluidity of the melt increased with an increase in wax content and in the binder content. The observed behavior can be rationalized as follows: The chosen measurement temperature of $120^{\circ} \mathrm{C}$ is $10{ }^{\circ} \mathrm{C}$ higher than the injection molding temperature but lower than the melting point of the urea in these compounds (ca. $\left.133{ }^{\circ} \mathrm{C}\right)$. This means that the 
urea most likely acted as solid filler and that the molten wax plus EVA phase enabled flow. The viscosity of a suspension of solids depends on the volume fraction of filler present as well as the viscosity of the liquid phase. The EVA and wax are miscible in the melt. Increasing the polymer content at a constant wax level decreases the filler content. This should lead to a decrease in the suspension viscosity, i.e. an increase in the observed MFI.

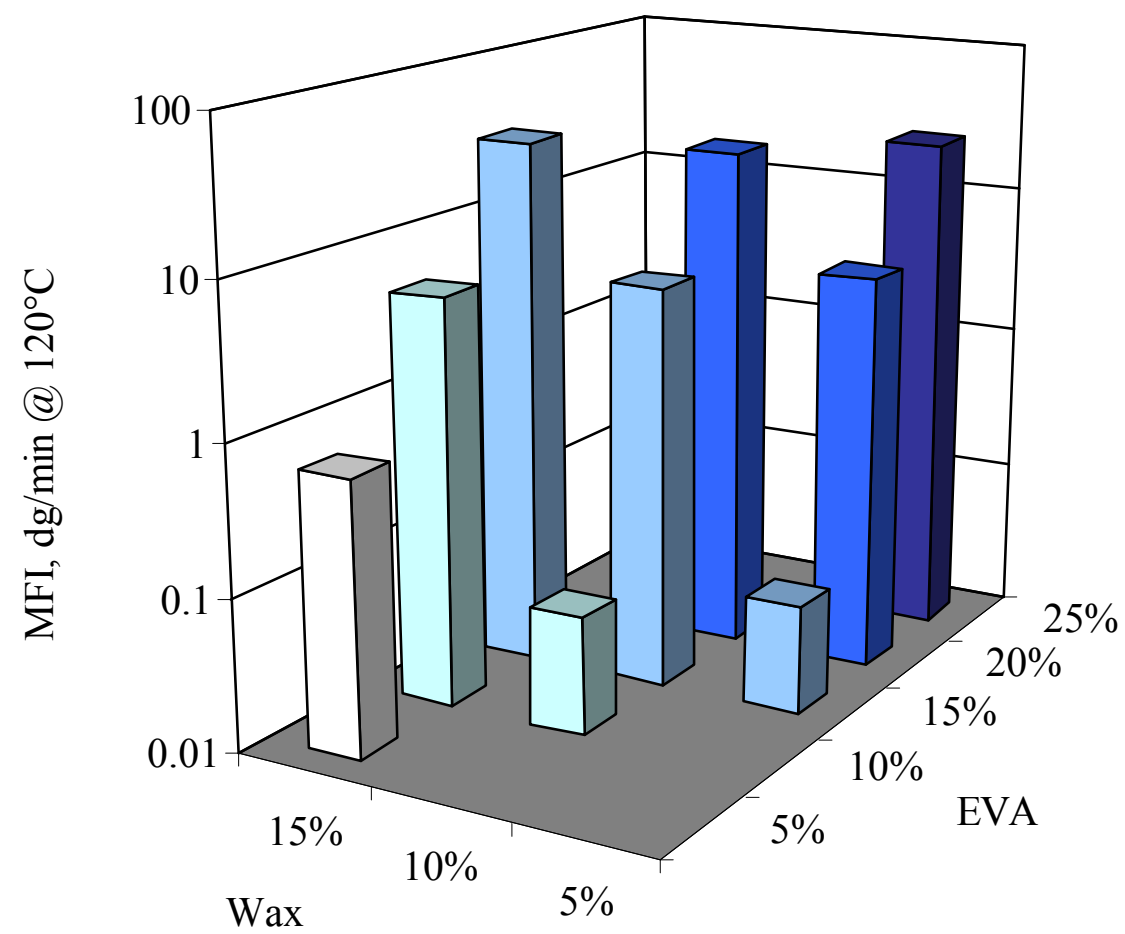

Figure 2. The effect of wax and binder content on the melt flow index of EVA-based compounds.

\subsection{Mechanical Properties}

The mechanical properties of the compound determine the "hardness" and the strength of the molded patterns. High stiffness is required to ensure that the investment pattern will retain its shape even when subjected to mechanical stress. The modulus of elasticity provides a measure of the material's stiffness. However, the ultimate mechanical properties of the pattern materials do not need to be outstanding. They must just be sufficient to prevent breakage during normal handling for the duration of the investment casting process. 


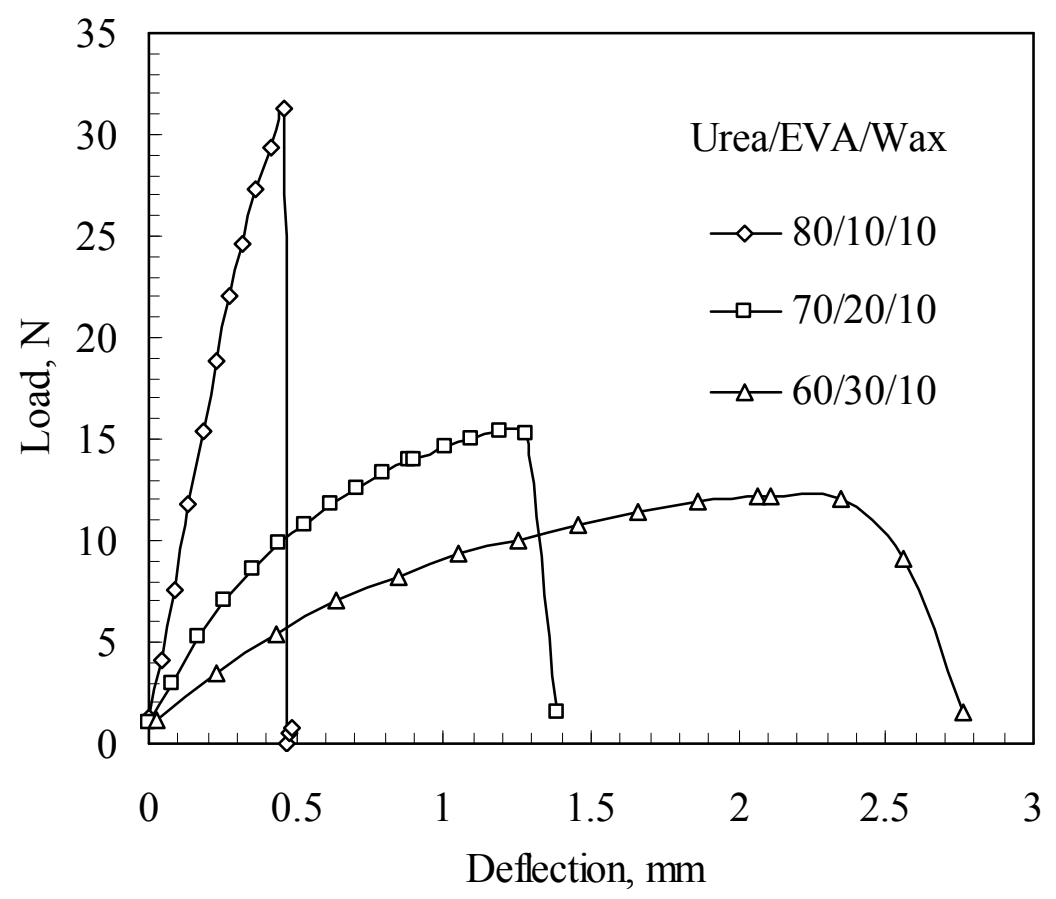

Figure 3. Effect of varying EVA content on the load deflection curve of EVA molding compound.

Three point bending test: The main advantage of the three point flexural test is that it can be used to characterizing very brittle materials as is the case presently. Figure 3 shows typical load versus deflection curves for EVA-based compounds. From such curves the flexural strain and stress were calculated using the standard equations described in ASTM D790. The flexural stress-strain response of the material was used to calculate the flexural strength, the modulus of elasticity and the flexural strain at break. However, even the raw load-deflection data provided an indication on the toughness and strength of the materials. Figure 3 shows the effect of increasing the EVA content from $10 \mathrm{wt} \%$ to $30 \mathrm{wt} \%$ while keeping the wax content constant. At $10 \mathrm{wt} \%$ EVA the response curve is typical for a very brittle material showing a catastrophic failure at low deflections. Increasing the binder content decreased the maximum load, increased the deflection at break, caused the failure to occur more gradually, and increased the fracture energy as indicated by the area under the stress-strain curve. This means that the nature of the material changed towards greater toughness as the polymer content was increased. Similar trends were observed with the $\mathrm{PVOH}$ compounds. 
Figure 4 shows the effect of wax and binder content on the flexural strength. Flexural strength decreased with increase in binder content in both the PVOH- and EVA-based compounds. The polymer content is the most important factor while the effect of wax is masked by the considerable scatter in the data. The PVOH-based compounds were generally significantly stronger than those based on EVA. This is primarily attributed to poor interfacial adhesion in the latter binder system.

Figure 5 shows the effect of composition on the modulus of elasticity (measure of stiffness) of the materials. The modulus of elasticity decreased as the binder content increased. The effect of increasing wax content is less apparent in the PVOH-based compounds compared to those based on EVA. In the latter case increasing wax also caused a clear decrease in stiffness. The binder phase should become stiffer with increasing wax content so this observation may be linked to a weakening of the interfacial adhesion.

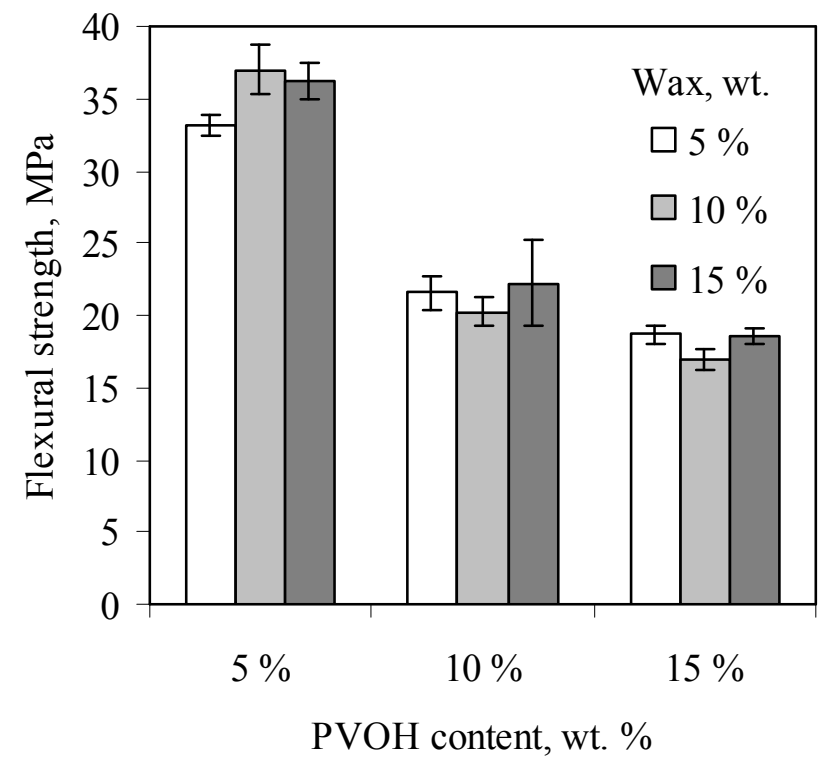

A

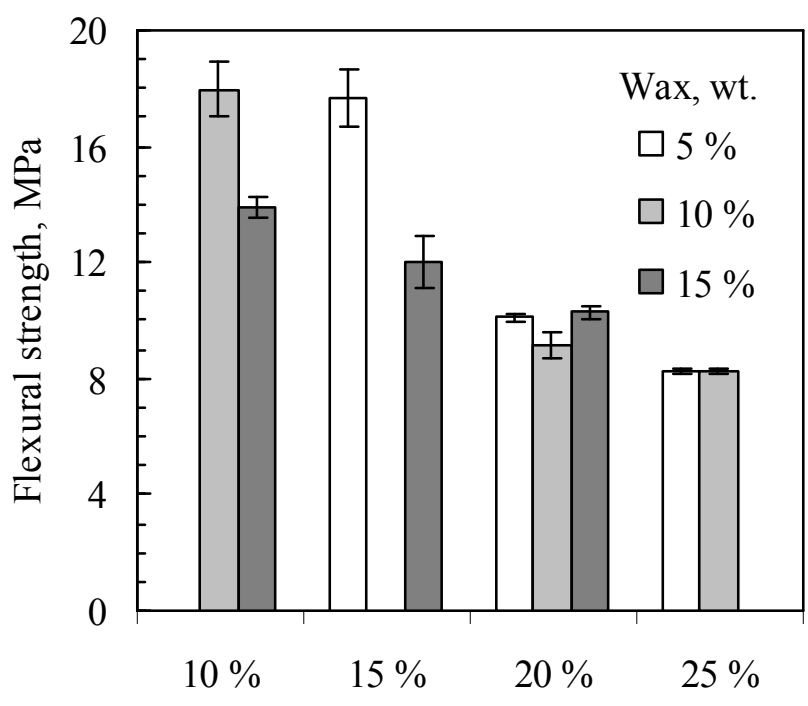

EVA content, wt. \%

Figure 4. Effect of wax and binder content on the flexural strength of (A) PVOH and (B) of EVA compounds. 
Charpy impact strength: Impact testing is a mechanical procedure used to evaluate the ability of a material or an object to withstand a high loading rate. This is quantified as the energy required to bring about fracture. Charpy impact tests were used to obtain a quantitative indication of the pattern material's toughness. The results are shown in Figure 6. The PVOH-based compounds showed significantly higher Charpy impact performance than the EVA-based materials. Impact strength increased with increasing binder content in both cases. The effect of wax in the two binders is diametrically opposed. In PVOH an increase in wax content caused a sharp decrease in impact properties while in the EVA-based compounds the impact strength improved. This can be explained if it is the polymer phase that imparts impact resistance. Adding wax increases the binder phase volume fraction. The decrease in interfacial adhesion with increasing wax content would not be detrimental as it actually facilitates deformation of the polymer binder phase at the microscopic level.

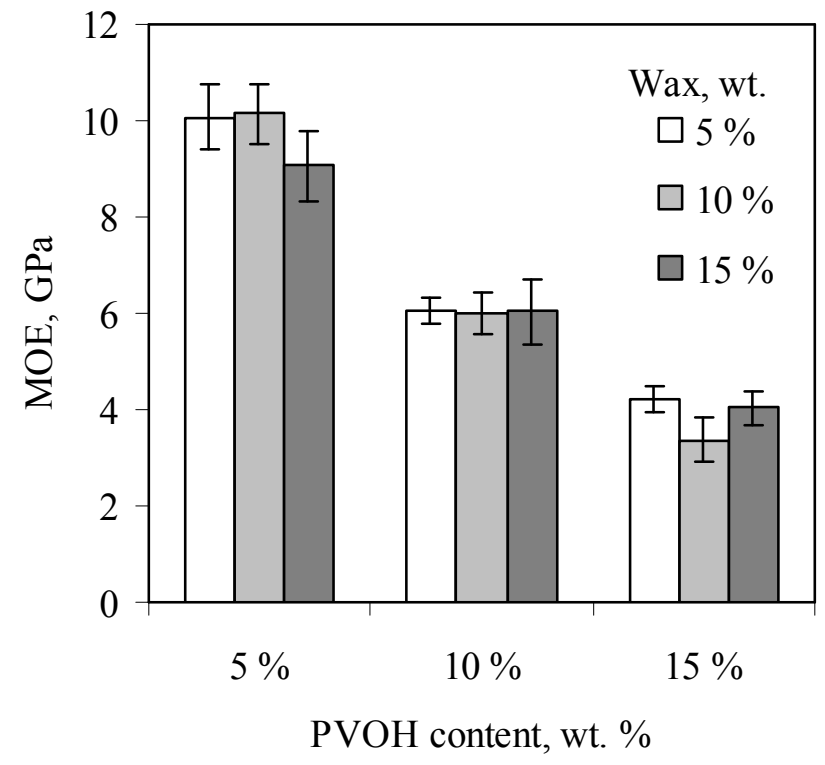

A

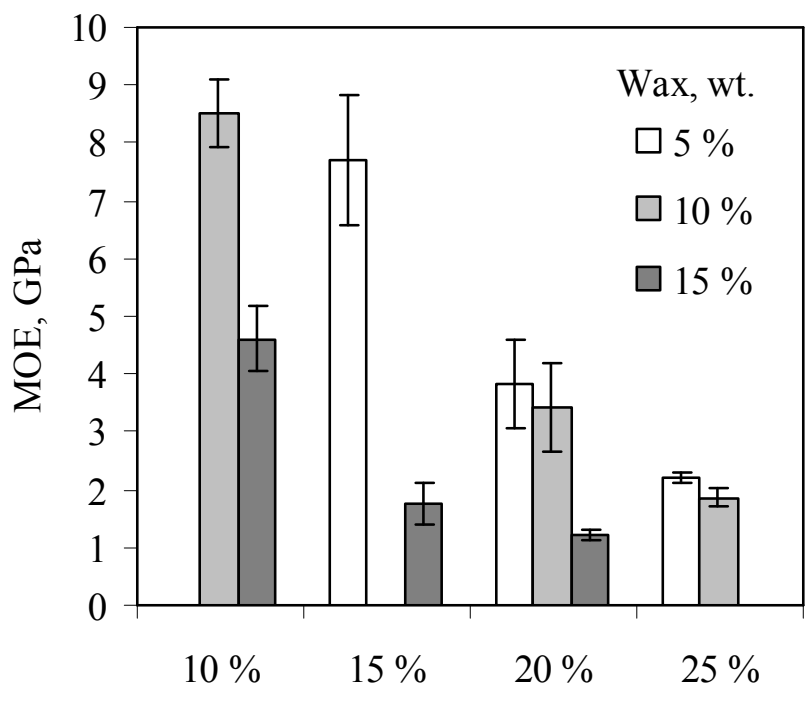

EVA content, wt. \%

B

Figure 5. Variation of the modulus of elasticity of (A) PVOH-based and (B) EVA-based compounds with wax and binder content. 


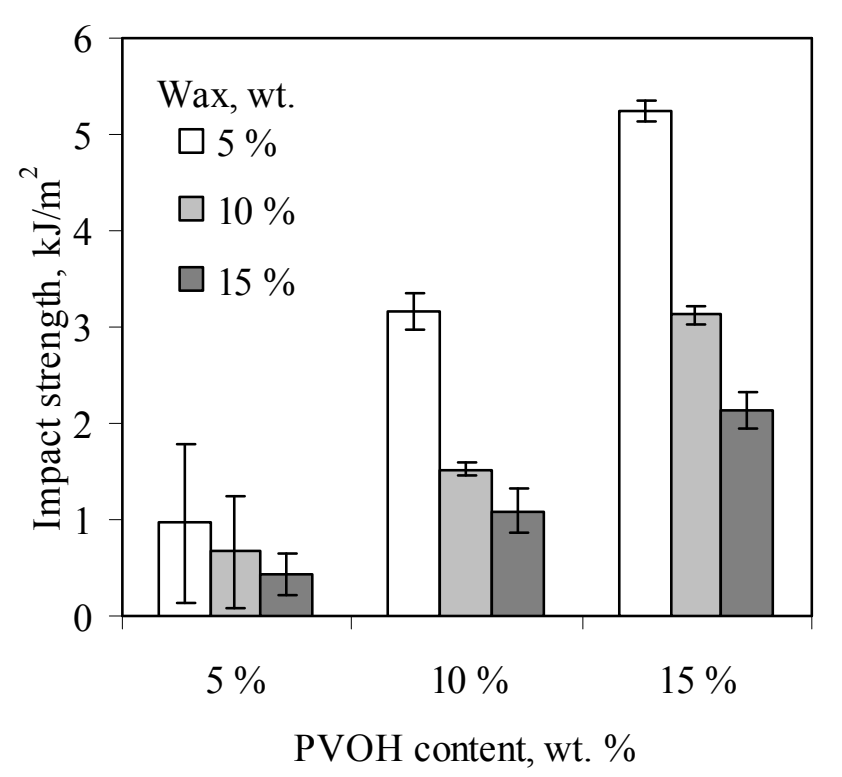

A

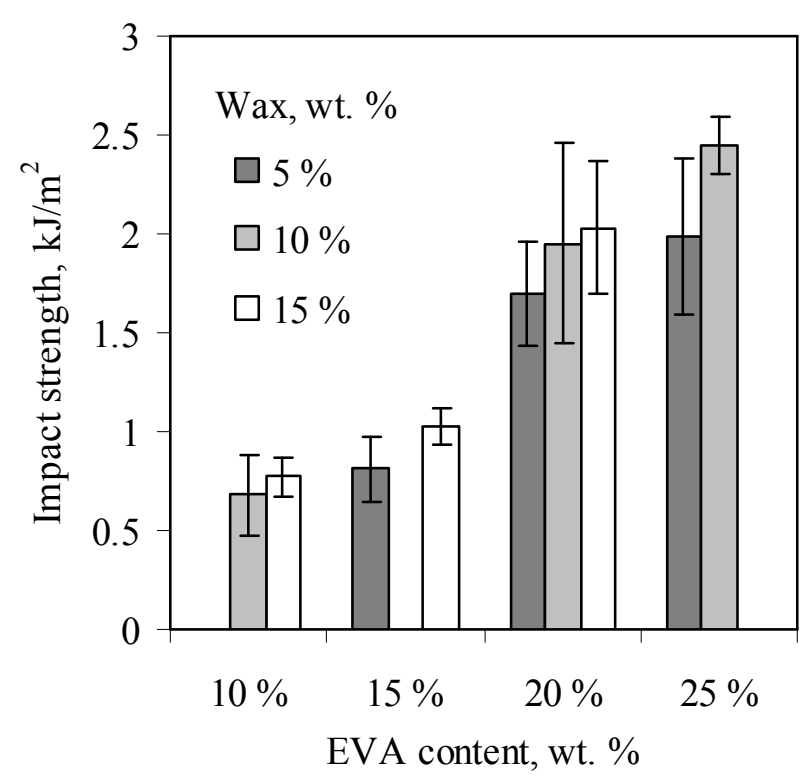

$\mathrm{B}$

Figure 6. Effect of composition on the unnotched Charpy impact strength of (A) PVOH-based and (B) EVA-based compounds.

\subsection{Softening Temperature, Thermal Expansion and Dynamic Mechanical Analysis}

The softening temperature and the thermal expansion are relevant with respect to the removal of the pattern material from the green ceramic shell. The softening point indicates the temperature where the material starts to loose its mechanical integrity before becoming fluid. A large thermal expansion can generate stress that may cause cracking of the friable green ceramic shell.

Vicat softening temperature: Vicat provides a relative assessment of the temperature where a material softens. In the standard test method described by ASTM 1525 it is determined as the temperature at which, under a specified load (10 $\mathrm{N}$ in the present study), a flat-ended needle enters to a depth of $1 \mathrm{~mm}$. Figure 7 reports data obtained with PVOH as binder. It shows that the softening temperature increases with a decrease in the polymer content and an increase in the wax content. The latter observation provides strong evidence that the wax is at least partially incorporated into the urea because the wax itself liquefies at lower temperatures $\left(<55^{\circ} \mathrm{C}\right)$. 


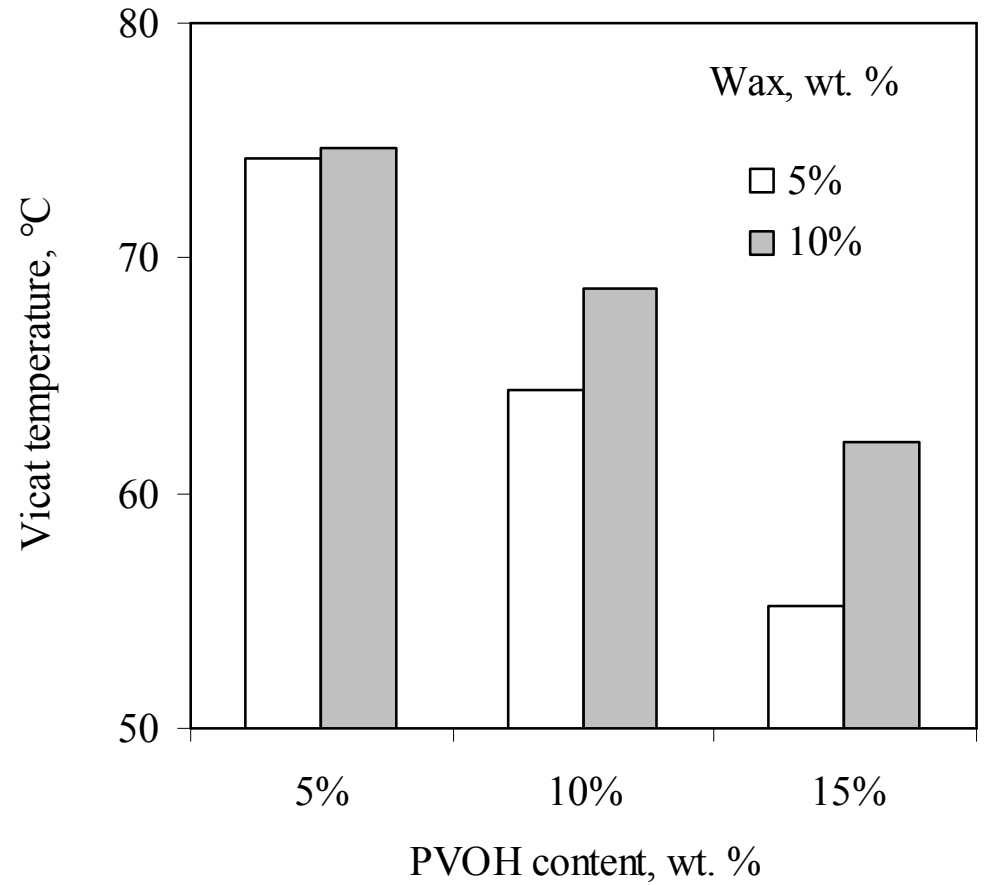

Figure 7. The effect of composition on the Vicat softening temperatures of PVOH-based compounds.

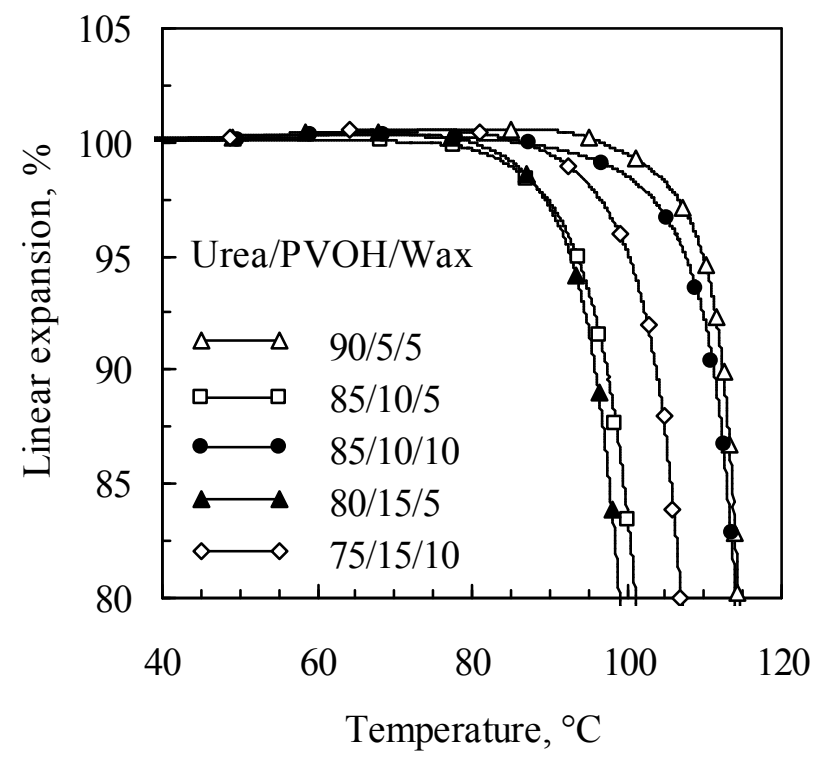

A

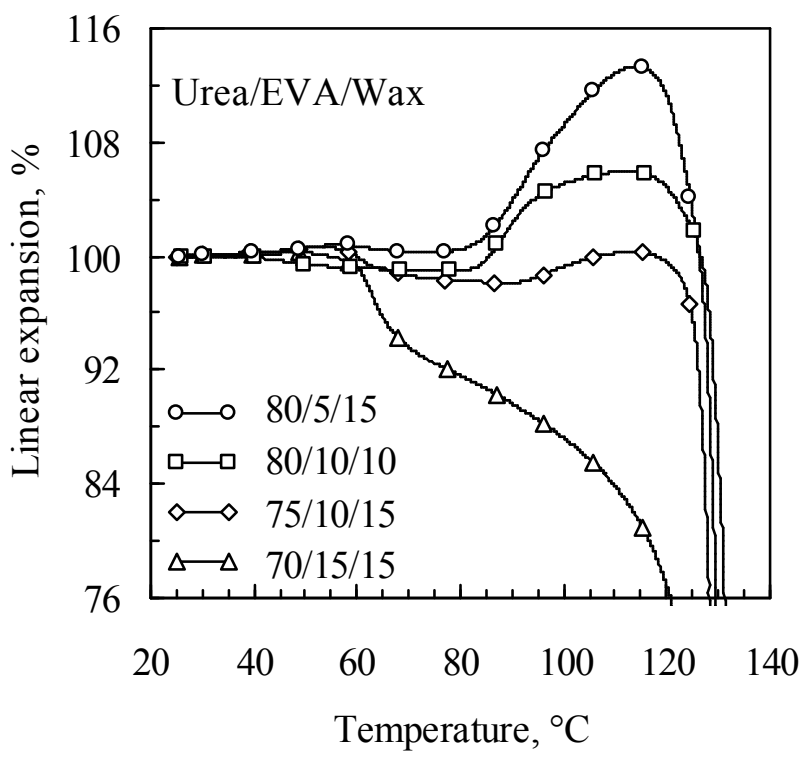

$\mathrm{B}$

Figure 8. Thermal expansion curves for selected (A) PVOH-based and (B) EVA-based compounds.

Thermal expansion: Figure 8 shows thermal expansion results obtained with the thermal mechanical analyzer (TMA). It is clear that the thermal expansion of the EVA-based compounds varies nonlinearly in the temperature range of interest $\left(25-100^{\circ} \mathrm{C}\right)$. The sharp decrease noted at the 
higher temperatures is an artifact related to the softening and melting of the compound's constituents. From a practical point of view it is probably more correct to consider the maximum expansion value attained. The results suggest that high wax contents cause high thermal expansion but that the effect is ameliorated by increasing the EVA content. These observations also point to a preference for the wax to accumulate in the EVA phase.

The PVOH-based compounds show only a slight expansion up to ca. $90{ }^{\circ} \mathrm{C}$ where after the material softened and the probe penetrated the material. This behavior is consistent with excess wax absorbing into the urea channels as it melts.

Dynamic mechanical analysis: Polymers are visco-elastic materials, i.e. they exhibit characteristic of both viscous liquids and elastic solids. Their mechanical properties vary with temperature and are also time-scale dependent. This temperature and time dependent relaxation behavior can be studied using stress-strain relationship generated by dynamic mechanical analysis (DMA) (Menard, 2003). This technique also provides indirect insight into the phase structure of the materials. The storages modulus (E') is a measure of the materials stiffness and is an important variable measured in DMA tests. Figure 9 shows the effect of composition for these the two binder systems studied. The storage modulus for the PVOH-based binder shows a continuous decrease over several decades in the temperature range $0{ }^{\circ} \mathrm{C}$ to ca. $125{ }^{\circ} \mathrm{C}$. This unexpected behavior suggests that the PVOH compounds act macroscopically as if they were single phase materials. It could be that PVOH solubilised in molten urea is, on rapid cooling, homogeneously trapped at a level approaching that of a molecular dispersion in the solid material.

In contrast, the EVA compounds show a stepwise drop in modulus as the temperature is increased. The first step coincides approximately with the expected melting range of the EVA and wax components. The second steep drop in storage modulus above $130{ }^{\circ} \mathrm{C}$ is due to the melting of the urea phase. The plateau value observed is consistent with a phase separated morphology with the urea crystals acting as solid filler and the polymer plus wax acting as binder. 


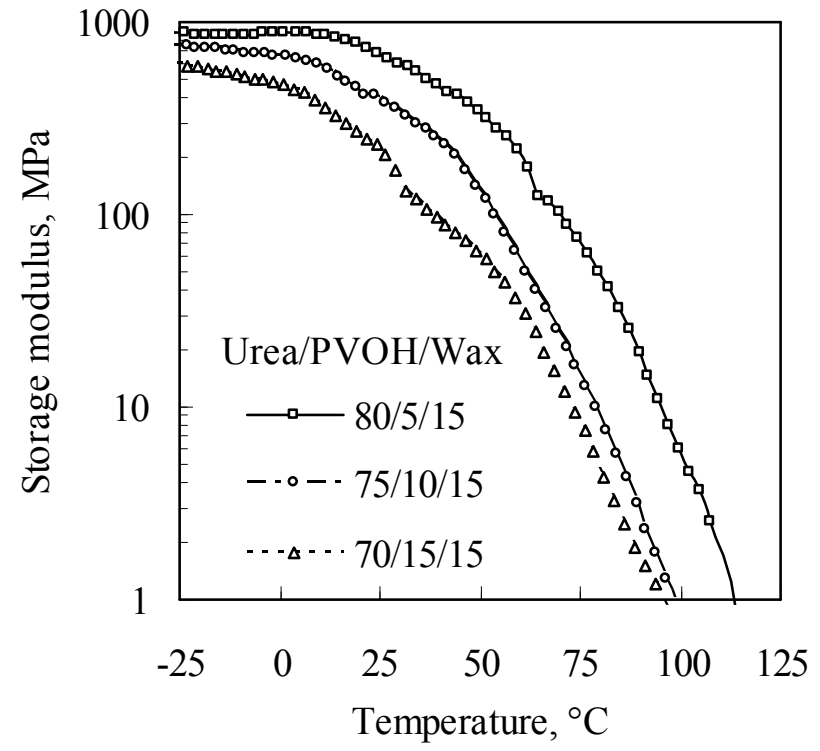

A

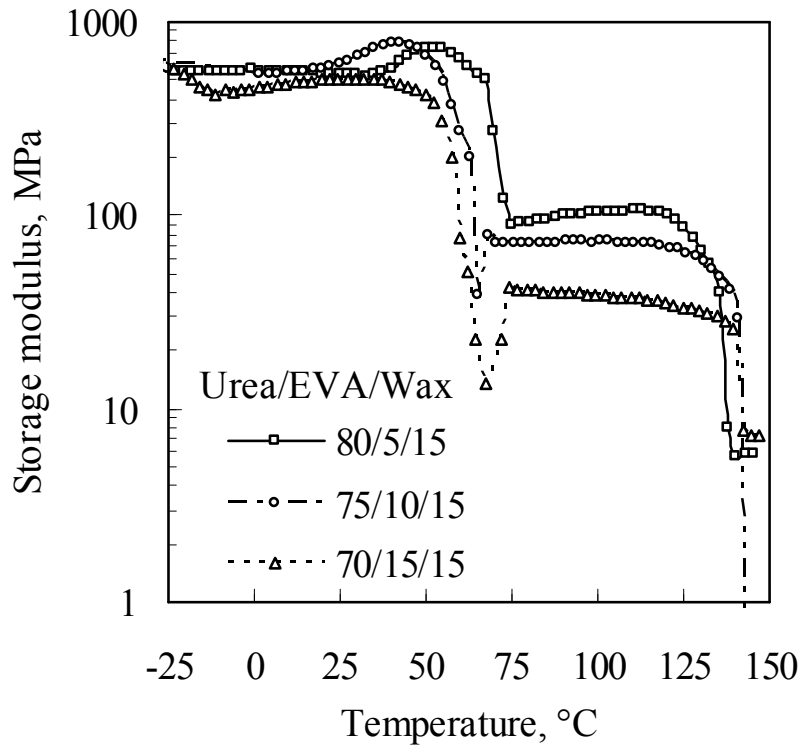

$\mathrm{B}$

Figure 9. The effect of polymer content on the storage modulus of (A) PVOH-based and (B) compounds EVA-based compounds.

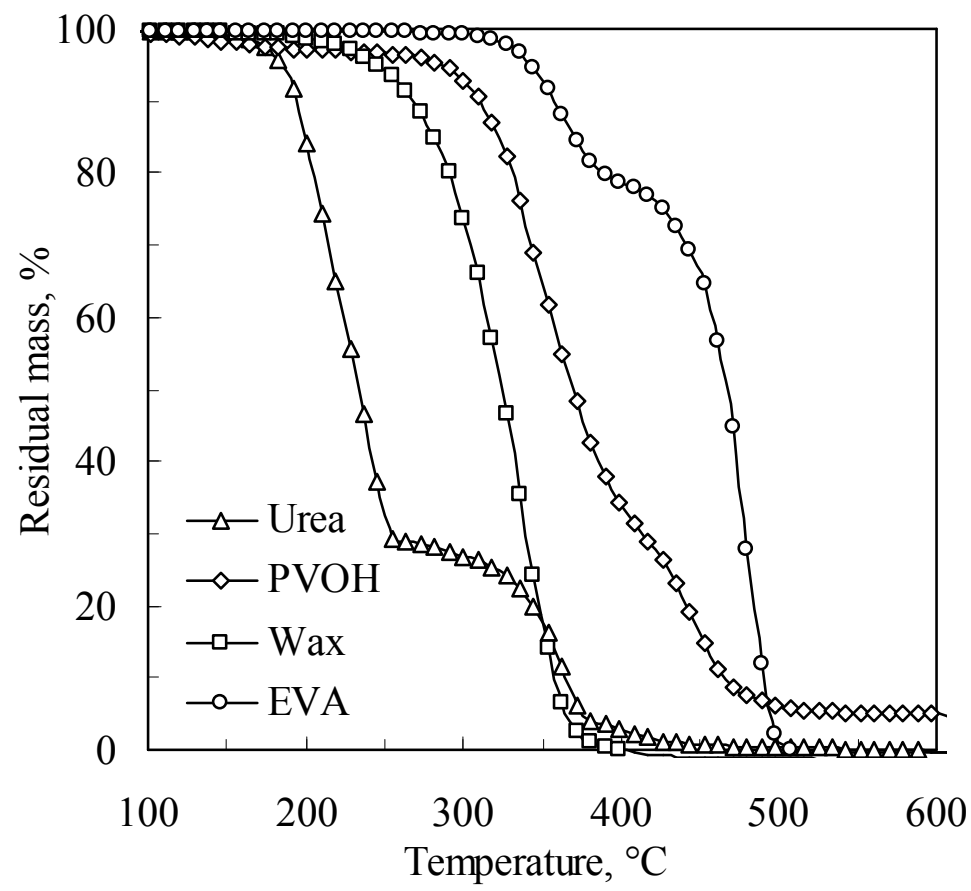

Figure 10. The mass loss versus temperature of virgin/pure compounds.

\subsection{Thermo-gravimetric Analysis}

The amount of ash residue from a molding compound generated during the firing process in investment casting process is a crucial parameter. Any ash that remains in the mould could react 
with the metal during the investing process and result in a poor surface finish. To ensure a good surface finish, the amount of ash content must be minimal, i.e. less than 3 wt. \%. Thermo gravimetric analysis (TGA) was used to study the change in mass of the materials on heating in an air atmosphere.

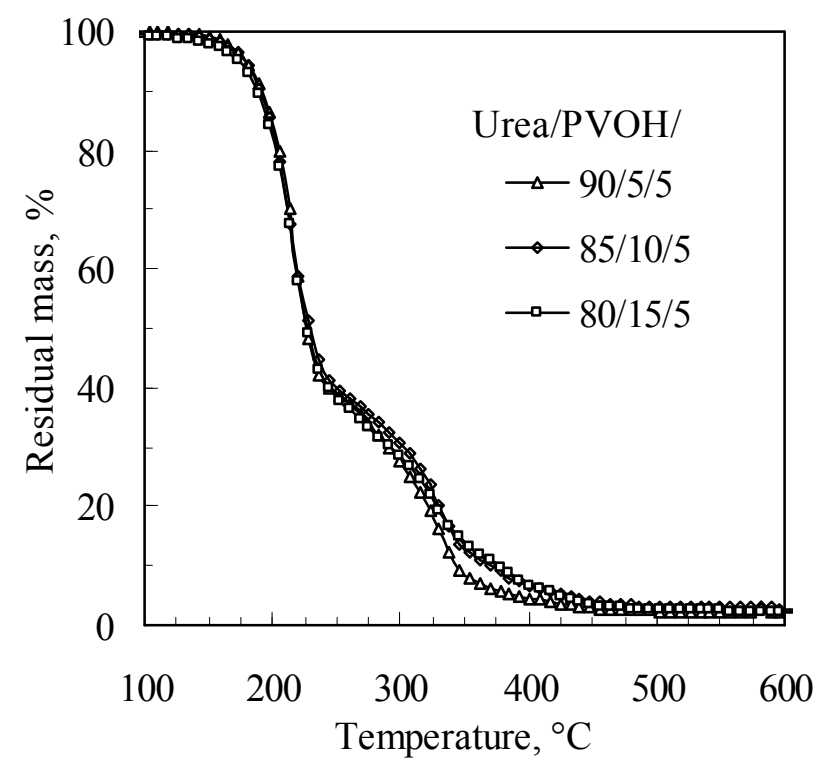

A

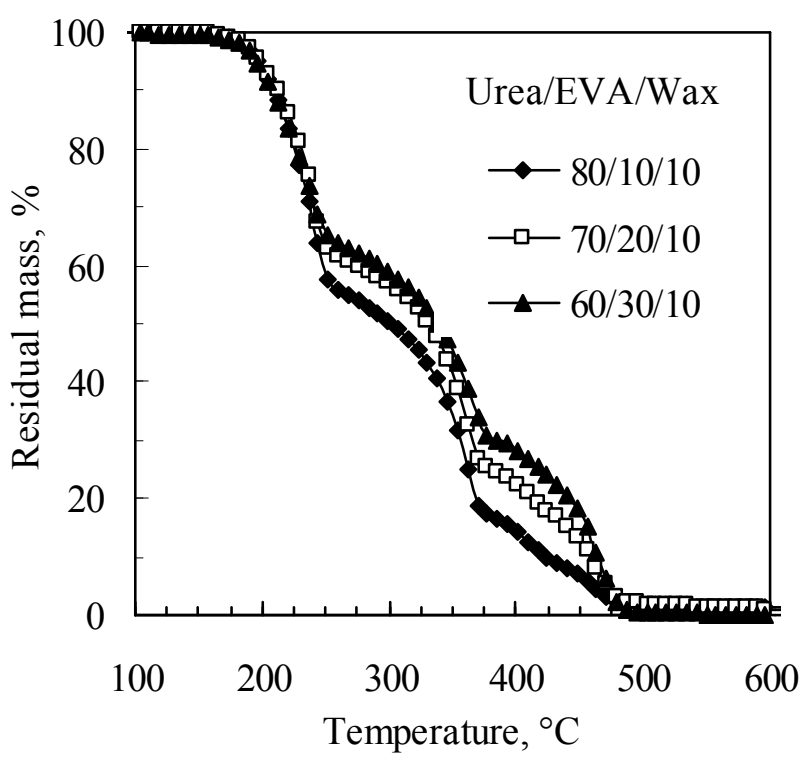

B

Figure 11. Mass loss versus temperature of (A) PVOH-based and (B) EVA-based compounds showing the effect of increasing polymer content.

The TG results for the pure components are shown in Figure 10. In the case of urea mass loss takes place in two major steps. The first commences in earnest at ca. $175^{\circ} \mathrm{C}$ yielding a residual mass of ca. 30 wt. $\%$ at $250{ }^{\circ} \mathrm{C}$. The second event reaches its maximum rate at ca. $350{ }^{\circ} \mathrm{C}$. The observed urea residue is attributed to condensation reactions that generate thermally stable and non-volatile compounds. However, the $<3 \mathrm{wt} \%$ ash target is attained at $400{ }^{\circ} \mathrm{C}$. The wax retains mass to higher temperatures. Mass loss occurs in a single step and is due to a combination of pyrolysis and evaporation. The other two components also degrade in two steps. EVA decomposes less easily compared to urea and wax. Virtually complete mass loss is achieved at $500^{\circ} \mathrm{C}$. The PVOH forms a non-volatile, temperature-stable char residue on pyrolysis. The $<3 \mathrm{wt} \%$ residue level target is only attained at temperatures above $850{ }^{\circ} \mathrm{C}$. 
Figure 11 shows the TG curves for selected PVOH and EVA compounds. The initial mass loss in both binder systems mimics the behavior observed for neat urea. For PVOH as binder, a residue plateau is observed owing to the tendency for PVOH to char. However, the ash level reached the 3 wt $\%$ level by ca. $470{ }^{\circ} \mathrm{C}$ at the highest binder content. Mass loss is slower with EVA as binder but the required ash level is reached at approximately the same temperature.

\section{Conclusions}

Two different polymer systems were evaluated as binders for urea-based pattern molding compounds. They comprised a low polarity EVA and a highly hydrophilic, plasticized PVOH. Paraffin wax was used as lubricant and as mould release agent. The effect of composition on selected thermo-mechanical properties, relevant to investment casting pattern molding compounds was studied. Measurements were done on as-molded dog bone test pieces machined to specified dimensions. This means that the reported results pertain to non-equilibrium phase behavior of these materials as generated by the injection molding process. It was found that the PVOH-based compounds generally featured enhanced mechanical properties, e.g. stiffness, strength, impact resistance, etc., compared to the EVA-based compounds. The observed behavior could be rationalized in terms of the affinities and interactions between the urea, wax and polymer phases. In the EVA compounds the wax and urea formed a homogeneous continuous phase that controlled physical properties in the solid state as well as the flow behavior at temperatures below $120{ }^{\circ} \mathrm{C}$. The urea crystals merely acted as solid filler particles. Poor mechanical properties but acceptable impact strength was attributed to weak interfacial adhesion between these two main phases.

The glycerol-plasticized PVOH-based formulations behaved as if they were single phase materials in the solid state. It is believed that the PVOH is at least partially soluble in molten urea. The rapid cooling rate enforced during injection molding could have trapped a homogeneous 
network of PVOH fibrils within the urea phase. This inference is supported by the fact that the storage modulus shows only a gradual change to lower values as the temperature is increased to the melting point of urea. It is also supported by the low apparent thermal expansion of the PVOHbased compounds. If the PVOH chains were present in non-equilibrium conformations, one would have expected to observe more extensive thermal expansion behavior. Neat wax formed a separate phase as its melting could be observed in the DSC trace. However, DSC also showed evidence for the presence of a higher melting clathrate phase at high wax contents. It is possible that, during slow heating, the expansion of molten wax was partially compensated for by the incorporation of the liquid within the urea crystal channels, i.e. by the formation of the clathrate inclusion compound. This would explain the much low thermal expansion observed for PVOH-based compounds compared to the EVA formulations.

\section{Acknowledgements}

Financial support for this research from Xyris Technology, Ceracast and the THRIP program of the Department of Trade and Industry and the National Research Foundation of South Africa is gratefully acknowledged. 


\section{References}

Black, J.T., DeGarmo, E.P., Kosher, R.A.: Materials and Processes in Manufacturing, Macmillan Publishing Company, New York, (1984)

Fielder, H., "Mechanical Properties of Pattern Waxes", Proceedings of the $43^{\text {rd }}$ Annual Technical Meeting, Investment Casting Institute, Paper No. 1, pp. 1-7 (1995)

Fielder, H., "The Relationship Between Wax Fillers and Resultant. Wax Physical Properties", Proceedings of the $46^{\text {th }}$ Annual Technical Meeting, Investment Casting Institute, Paper No. 2, Orlando, Florida (1998)

US Pat. 4,939,187 (1990), Fujita, T., "Pattern Material for Making Foundry Patterns for use in Investment Casting Process".

George, W.: Handbook of Plasticizers, Chemtec Publishing, New York, (2004)

Jang, J., Lee, D.K., "Plasticizer Effect on the Melting and Crystallization Behavior of Polyvinyl Alcohol”, J. Polym. Sci. 44, 8139-8146 (2003)

Menard, K.P.: Dynamic Mechanical Analysis: A Practical Introduction”, CRC Press LLC, Boca Raton (1999)

Sabau, A.S., Viswanathan, S., "Material properties for predicting wax pattern dimensions in investment casting”, Materials Science and Engineering A, 362, 125-134 (2003)

Sekiguchi, K., Obi, N., "Studies on Absorption of Eutectic Mixture. I. A Comparison of the Behavior of Eutectic Mixture of Sulfathiazole and that of Ordinary Sulfathiazole in Man”, Chem. Pharm. Bull., 9, 866-878 (1961)

White, M.A., “Origins of Thermodynamic Stability of Urea:Alkane Inclusion Compounds”, Can. J. Chem., 76, 1695-1698 (1998) 